\title{
8
}

\section{im

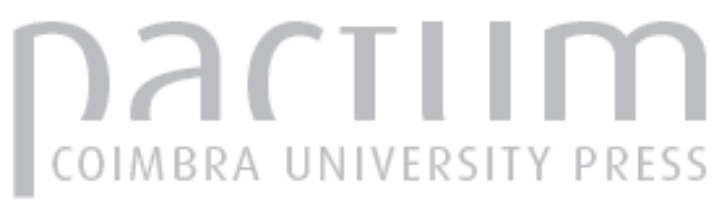

\section{Catálogo dos manuscritos e dos impressos musicais do Fundo António de Lima Fragoso}

Publicado por: Imprensa da Universidade de Coimbra

URL persistente:

URI:http://hdl.handle.net/10316.2/43036

DOI:

DOI:https://doi.org/10.14195/1647-8436_46_47_14

Accessed : $\quad$ 26-Apr-2023 14:34:02

A navegação consulta e descarregamento dos títulos inseridos nas Bibliotecas Digitais UC Digitalis, UC Pombalina e UC Impactum, pressupõem a aceitação plena e sem reservas dos Termos e Condições de Uso destas Bibliotecas Digitais, disponíveis em https://digitalis.uc.pt/pt-pt/termos.

Conforme exposto nos referidos Termos e Condições de Uso, o descarregamento de títulos de acesso restrito requer uma licença válida de autorização devendo o utilizador aceder ao(s) documento(s) a partir de um endereço de IP da instituição detentora da supramencionada licença.

Ao utilizador é apenas permitido o descarregamento para uso pessoal, pelo que o emprego do(s) título(s) descarregado(s) para outro fim, designadamente comercial, carece de autorização do respetivo autor ou editor da obra.

Na medida em que todas as obras da UC Digitalis se encontram protegidas pelo Código do Direito de Autor e Direitos Conexos e demais legislação aplicável, toda a cópia, parcial ou total, deste documento, nos casos em que é legalmente admitida, deverá conter ou fazer-se acompanhar por este aviso.

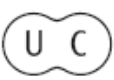




\section{BOLETIM DA \\ BIBLIOTECA GERAL DA UNIVERSIDADE DE COIMBRA}

VOL. 46/47 (2015/2016)

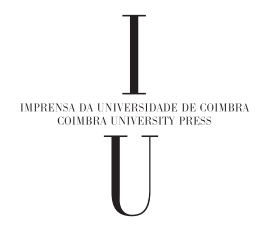




\section{Catálogo dos Manuscritos e dos Impressos Musicais do Fundo António de Lima Fragoso}

O catálogo dos manuscritos e impressos musicais do Fundo António de Lima Fragoso encontra-se organizado nas seguintes categorias:

1. Música manuscrita: 1.1. Música vocal: 1.1.1. Coro a capella; 1.1.2. Música vocal com acompanhamento: canto acompanhado (Lieder, canções). 1.2. Música instrumental: 1.2.1. Música para orquestra; 1.2.2. Música de câmara; 1.2.3. Música para instrumento solo: 1.2.3.1. Piano; 1.2.3.2. Violino; 1.2.3.3. Violoncelo. 1.3. Música religiosa. 1.4. Exercícios de composição. 1.5. Manuscritos de autoria não determinada.

2. Música impressa: 2.1. Música vocal: 2.1.1. Canto acompanhado (Lieder, canções). 2.2. Música instrumental: 2.2.1. Música para orquestra; 2.2.2. Música de câmara; 2.2.3. Música para piano.

3. Impressões e fotocópias: arranjos e orquestrações.

Em cada classe, as referências encontram-se por título em ordem alfabética.

As partes cavas classificam-se junto das respetivas partituras gerais, sempre que estas se encontram disponíveis no Espólio, dentro da mesma categoria, segundo o tipo material; no caso de não dispormos, 
na respetiva categoria, da partitura geral, classificaram-se as partes como partituras para instrumento solo.

Cada referência, encabeçada por título uniforme (título / forma da composição, meio de expressão, tonalidade/modalidade), contém os seguintes elementos de descrição': nome (datas) do autor/compositor. Título na fonte. Tipo de recurso. Menção de outras responsabilidades. Local e data de produção ou publicação. Descrição física, extensão e dimensões. Título e conteúdo (forma da composição, instrumentação, tom/modo e tempo de andamento no incipit musical, sempre que possível e quando indicados). Observações. Identificador do documento (cota atual na Biblioteca Geral da Universidade de Coimbra, Portugal).

\section{Música manuscrita}

\subsection{Música Vocal}

\subsubsection{Coro a capella}

\section{CORO DOS PEREGRINOS}

FRAGOSO, ANTÓNIO, (1897-1918). Coro dos peregrinos [Música manuscrita]. [1914]. Partitura ms. (1 f.) ; 28,8 x 20,8 cm.

Coro dos peregrinos, SSA, Mi M, largo magestoso, «com boca fechada» Autógrafo, notação a lápis de carvão com marcas a tinta, provavelmente de revisão. Também disponível partitura ms. da transcrição para piano.

ALF M.M. 1.2 (1)

1 Conforme normas NP 405-1, Informação e Documentação - Referências bibliográficas : documentos impressos. Monte da Caparica : IPQ., 1994 e NP 405-3, Informação e Documentação - Referências bibliográficas : documentos não publicados. Monte da Caparica: IPQ., 2000, complementadas pelas das orientações do RISM (Répertoire International des Sources Musicales) para a descrição e catalogação das fontes musicais. 


\subsubsection{Música Vocal com Acompanhamento: Canções}

\section{CANÇÃO DA FIANDEIRA}

(Ver: Canções do sol poente)

\section{CANÇÕES DO SOL POENTE}

FRAGOSO, António, (1897-1918). [Canções do sol poente] [Música manuscrita]. [1917-1918]. Partitura ms. [16 f.] ; 35,2 x 27,0 cm.

Canção da fiandeira. Canções, S pf, Fa \# M, não muito depressa; expressivo Embalando o menino. Canções, S pf, Re b M, num ritmo de berço embalando Modas da serra. Canções, S pf, Fa \# m, tristemente; expressivo A primeira romaria. Canções, S pf, La M, com alegria de festa em dia de romaria; um pouco mais expressivo

A manhã da cerração. Canções, S pf, Do M, lentamente e como numa evocação

O Natal no céu. Canções, S pf, La m, devagar e apaixonadamente; e muito expressivo

A Senhora dos Remédios. Canções, S pf, Re M, vagaroso

Cantigas do lenço. Canções, S pf, Si m, com profunda melancolia / muito expressivo

Música para canto e piano, sobre versos de António Correia de Oliveira. Cópia; notação e letra muito cuidadas, a tinta preta. Também disponíveis outra partitura ms. apenas das peças «Embalando o menino» e «A manhã de cerração» e a publicação, com revisão de Fernando Lopes-Graça.

ALF M.M. 1.2 (2)

\section{CANÇÕES DO SOL POENTE}

FRAGOSO, António, (1897-1918). Embalando o menino ; A manhã de cerração [Música manuscrita]. [1917-1918]. Partitura ms. [5 p. em duas f. dobr.] ; $28,6 \times 21,5 \mathrm{~cm}$.

Embalando o menino. Canções, S pf, Re b M, tempo de Berceuse A manhã de cerração. Canções, $S$ pf, Do $M$

Música para canto e piano, sobre versos de António Correia de Oliveira. Cópia cuidada, a tinta preta, de duas das oito peças do ciclo Canções 
do sol poente. Título e autor na p. de título, a tinta azul, em letra de mão diferente. Pert.: Viriato Fragoso, Pocariça. Também disponíveis: partitura ms. do ciclo completo; publicação, com revisão de Fernando Lopes-Graça (1971).

\section{ALF M.M. 1.2 (3)}

\section{CANTIGAS DO LENÇO}

(Ver: Canções do sol poente)

\section{CHANSON D'AUTOMNE. Canções, Fa \# m}

FRAGOSO, António, (1897-1918). Chanson d'Automne [Música manuscrita]. [1917]. Partitura ms. (2 p. em 1 f. dobr.) ; 30,0 x 22,8 cm.

Chanson d'Automne. Canções, S pf, Fá \# m, modéré Autógrafo rasurado e emendado. Notação e letra a lápis. Fernando Lopes-Graça (1971) integrou esta peça no ciclo Poèmes saturniens, transposta para Mi menor na publicação. Também disponível o manuscrito da partitura das duas primeiras peças do ciclo Poèmes saturniens.

\section{ALF M.M. 1.2 (4)}

\section{LES COQUILLAGES. Canções, Lá m}

FRAGOSO, António, (1897-1918). Les coquillages ; Triste était mon âme [Música manuscrita]. [1917]. Partitura ms. [6 p.] ; 30,0 x 22,7 cm.

Les coquillages. Canções, S pf, Lá m Triste était mon âme. Canções, S pf, Mi m Música para canto e piano sobre poesias de Paul Verlaine. Autógrafo assinado; notação e letra a lápis; incompleto, apenas p. 3-8, faltando as p. iniciais e o final da peça «Triste était mon ame». Também disponível publicação com revisão de Fernando Lopes-Graça (1971); «Triste était mon âme» encontra-se transposto para Ré menor.

ALF M.M. 1.2 (5)

\section{EMBALANDO O MENINO}

(Ver: Canções do sol poente) 


\section{A MANHÃ DE CERRAÇÃO}

(Ver: Canções do sol poente)

\section{MODAS DA SERRA}

(Ver: Canções do sol poente)

\section{O NATAL NO CÉU}

(Ver: Canções do sol poente)

\section{POĖMES SATURNIENS. Canções}

FRAGOSO, António, (1897-1918). Poèmes saturniens [Música manuscrita]. 1917. Partitura ms. (8 p.) ; $35,0 \times 27,0 \mathrm{~cm}$.

Soleils couchants. Canções, S pf, Mi b m, lent, dans une atmosphère de mystère

Sérénade. Canções, S pf, Fa m, modérément animé

Música para canto e piano sobre poesias de Paul Verlaine. Cópia autógrafa(?); notação e letra muito cuidadas, a tinta preta, com rasuras e correções a tinta azul e sublinhados a lápis color vermelho. Pert.: Viriato Fragoso, Pocariça. Também disponível publicação, com revisão de Fernando Lopes-Graça; a peça «Sérénade», encontra-se transposta para Mi b m.

ALF M.M. $1.2(6)$

\section{A PRIMEIRA ROMARIA}

(Ver: Canções do sol poente)

\section{A SENHORA DOS REMÉDIOS}

(Ver: Canções do sol poente)

\section{SÉRÉNADE}

(Ver: Poèmes saturniens)

\section{SOLEILS COUCHANTS}

(Ver: Poèmes saturniens) 


\section{TRISTE ÉTAIT MON ÂME}

(Ver: Les coquillages)

\section{VINDIMA. Canções, Mi M}

FRAGOSO, António, (1897-1918). Vindima [Música manuscrita] : poesia de Azul. [1915?]. Partitura ms. [2 p.] ; 30,0 x 22,8 cm.

Vindima. Canções, A pf, Mi M

Manuscrito a lápis em folha colada no final do rascunho da partitura da Petite suite para piano. Data da composição da Petite suite. Incipit literário: Bem cedo começ'a vindima, o verão correu calmo....

\section{ALF M.M. $1.2(22 / 23)$}

\subsection{Música Instrumental}

\subsubsection{Música para Orquestra}

\section{NOTURNOS, orquestra, Mi b M}

FRAGOSO, António, (1897-1918). Nocturno [Música manuscrita] : para orquestra. Lisboa, 1918. Partitura ms. (25 p.) ; 34,7 x 27,2 cm.

Noturnos, orch (2fl 2ob cor ing 2cl 2fag 4cor harp 2vl vla vlc cb), Mi b M Partitura assinada e datada; escrita cuidada a tinta negra, com correções e indicações a lápis de carvão e a lápis color azul, de outra mão; suporte de papel «Prosper Colas - Paris», de 14 pentagramas. Trata-se da partitura geral da versão orquestral do Nocturno em Ré b $M$, para piano. Dedicatória à cabeça da p. de tít.: "Ao meu Mestre Snr. Luiz de Freitas Branco". Com a anot.: "Tocado pela grande orquestra do maestro Pedro Blanch, em sua festa artística, em 16-3-919 / Tocado pela orquestra sinfónica do maestro Fernandes Fão, no Politeama, a 19-3-1922". Também disponíveis: partes cavas ms.; parte de harpa ms.; rascunho incompleto da partitura geral; publicação (partitura e partes cavas) com revisão de Jorge Croner de Vasconcelos (1968).

ALF M.M. 1.1 (f. 228-241) 


\section{NOTURNOS, orquestra, Mi b M}

FRAGOSO, António, (1897-1918). Nocturno [Música manuscrita] : [para orquestra]. [1918]. Partitura ms. (15 p.) ; 22,2 x 29,5 cm.

Noturnos, orch (2fl ob cor ing $2 \mathrm{cl}$ em Si b 2fag 4cor em Fá harp 2vl vla vlc cb), Mi b M

Rascunho da partitura geral do Noturno em Mi bemol Maior para orquestra, incompleto, faltando as p. 3-4 e 13-14. Escrita a lápis em suporte de papel «Thomar», de 14 pentagramas. Também disponíveis: partitura geral e partes cavas ms.; parte de harpa ms.; publicação (partitura e partes cavas) com revisão de Jorge Croner de Vasconcelos (1968).

\section{ALF M.M. 1.2 (7)}

\section{NOTURNOS, orquestra, Mi b M}

FRAGOSO, António, (1897-1918). Nocturno em mib [Música manuscrita] : [para orquestra]. [1918]. 18 pc ; dim. máx. 25,0 x 32,5 mm.

Noturnos, orch (1fl 2fl 1ob 2ob cor ing 1cl em Si b 2cl em Si b 1 fag 2 fag 1cor em Fá 2cor em Fá 3cor em Fá 4cor em Fá harp 1vl 2 l vla vlc cb), Mi b

Partes cavas ms., a tinta preta com indicações a lápis de carvão. Papel «L.J. \& C.ie Basseau», de 14 pentagramas; a parte de harpa em papel de proveniência e dimensões diferentes. Também disponíveis: rascunho da partitura geral, incompleto; partitura geral ms.; parte de harpa ms.; publicação (partitura e partes cavas) com revisão de Jorge Croner de Vasconcelos (1968).

\section{ALF M.M. 1.2 (8)}

\section{NOTURNOS, orquestra, Mi b M}

FRAGOSO, António, (1897-1918). Nocturno [Música manuscrita] : harpa. 1918. 1 pc ms. [5 p.] ; $34,6 \times 27,0 \mathrm{~cm}$.

Noturnos, orch (harp), Mi b M

Parte de harpa do Nocturno em Mi b M, para orquestra. Cópia cuidada, a tinta preta, rubricada no final (rubrica indecifrável), com correções e indicações a tinta vermelha e a lápis de carvão. Suporte de papel «Prosper Colas - Paris», de 12 pentagramas. Também disponíveis: partitura 
geral ms. e um rascunho da partitura geral, incompleto; partes cavas ms.; publicação com revisão de Jorge Croner de Vasconcelos (1968).

ALF M.M. 1.1 (f. 242-245)

\subsubsection{Música de Câmara}

\section{DANÇAS, quinteto de cordas, harpa e piano}

FRAGOSO, António, (1897-1918). [Dança?] [Música manuscrita] : [para orquestra de cordas]. [1917?]. Partitura ms. (2 p. em 1 f. dobr.) ; 35,3 x 27,2 cm.

Dança, orch (vl1 vl2 vla vlc cb pf harp), I: muito lento; II: expressivo e crescendo sempre

Título retirado de obra de referência (Prates, 2014). Possível autógrafo, incompleto; notação cuidada a tinta preta; suporte de papel «Prosper Colas - Paris», de 18 pentagramas. Também disponíveis: partitura ms. a lápis ( 2 p.) e a tinta ( 2 p.), inacabada, sem parte de piano, para quinteto de cordas e harpa.

\section{ALF M.M. 1.2 (9)}

\section{DANÇAS, quinteto de cordas e harpa}

FRAGOSO, António, (1897-1918). [Dança?] [Música manuscrita] : [para orquestra de cordas, com harpa]. [1917?]. Partitura ms. [4 p. em 1 f. dobr.] ; $35,3 \times 27,2 \mathrm{~cm}$.

Dança, orch (vl1 vl2 vla vlc cb harp)

Título retirado de obra de referência (Prates, 2014). Manuscrito a lápis e a tinta, porventura com dois andamentos, ambos inacabados; notação a lápis de carvão (p. 1-2 e 4) e a tinta preta (p. 3); suporte de papel «Prosper Colas - Paris», de 18 pentagramas. Também disponível cópia cuidada, incompleta, da composição para piano (em branco), harpa e orquestra de cordas.

ALF M.M. 1.2 (10)

\section{NOTURNOS, piano e harpa, Re b M}

FRAGOSO, António, (1897-1918). Nocturno [Música manuscrita]. Outubro 1917. Partitura ms. $(5,2$ p.) ; $30,0 \times 22,8 \mathrm{~cm}$. 
Noturnos, pf, harp, Ré b M, lento e expressivo

Partitura autógrafa a lápis, do Nocturno em Ré bemol Maior, para piano e harpa, seguida de rascunho a lápis da mesma peça para harpa, incompleto, com rascunhos de composição. O mesmo caderno contém um manuscrito da partitura para piano, datado de 1917, em letra muito cuidada, incompleto, apenas 37 compassos. Também disponíveis: partitura geral, partes cavas ms. e publicação da versão orquestral, em Mi b M.

\section{ALF M.M. 1.1 (f. 195-198)}

\section{SONATAS, piano e violino, RÉ M}

FRAGOSO, António, (1897-1918). Sonata em ré [Música manuscrita] : para piano e violino : op.3. Lisboa, 1917. Partitura ms. (16 p.) ; $34,8 \times 27,3 \mathrm{~cm}$.

Sonatas. Allegro, pf vl, Ré M, I: magestoso

Cópia autógrafa do primeiro andamento da Sonata em Ré (Sonata inacabada); escrita muito cuidada, a tinta preta nas p. 1-4 (87 compassos) e, a partir da p. 5 (compassos 88 a 277), originalmente a lápis de carvão, passada a tinta azul, possivelmente em época mais recente para meIhorar a leitura; segue-se o manuscrito, a lápis, do início do segundo andamento (39 compassos, p. 15-16), inacabado, acrescentado em data posterior. Papel «Prosper Colas - Paris». Contém anotações a lápis e indicações que indiciam revisão e provavelmente a preparação para publicação. Pert.: Viriato Fragoso, Pocariça. Publicada com o título Allegro da sonata (inacabada) em ré Maior: para violino e piano, com revisão de Artur Santos e Lídia de Carvalho (1971).

\section{ALF M.M. 1.2 (11)}

\section{SUITE PARA VIOLINO E PIANO}

(Ver: Suite romantique)

\section{SUITE ROMANTIQUE, piano e violino}

FRAGOSO, António, (1897-1918). [Suite romantique] [Música manuscrita]. [1916]. 1 pc ms.: (vl) ; 34,9 x 27,2 cm.

Prélude, pf vl, Do $M$, moderé

Intermezzo, pf vl, Sol m, très passioné 
Berceuse, pf vl, Fá $M$, très modéré

Nocturne, pf vl, Si b m, calme et doucement

Título com base em documentação do Fundo ALF e na publicação. Manuscrito autógrafo apenas da parte de violino da Suite para violino e piano (ou Suite romantique); notação a tinta negra, com rasuras e anots. ms. a lápis de carvão e a tinta azul, sobre papel «Prosper Colas - Paris». Também disponíveis: transcrição do «Nocturno» para piano (dois manuscritos); publicação do Noturno, sob o título «Nocturno em Sib menor» (Composições para piano. $2 .^{\circ}$ caderno, 1923); versão (?) para orquestra de cordas por Vasco Mendonça, 2012, em fotocópia.

\section{ALF M.M. 1.1 (f. 183-184)}

\section{TRIO, violino, violoncelo e piano, Do \# m}

FRAGOSO, António, (1897-1918). Trio [Música manuscrita] : op. 2. Lisboa, 1916. 2 pc ms.: (vl, vlc) ; $35,2 \times 27,0 \mathrm{~cm}$.

Trio, vl vlc e pf, Do \# m, I: Allegro moderato; II: Muito lento; III: Scherzo, muito vivo; IV: Final, allegro vivo.

Manuscritos autógrafos das partes de violino e violoncelo, faltando a parte de piano; notação a tinta negra, com anots. ms. a lápis de carvão; em papel «Prosper Colas - Paris», de 12 pentagramas. Publicação da partitura geral, com revisão de Luís Filipe Pires, também disponível.

\section{ALF M.M. 1.1 (f. 165-172)}

\subsubsection{Música para Instrumento Solo}

\subsubsection{Música para Piano}

\section{ALVORADA NO CAMPO, piano}

FRAGOSO, António, (1897-1918). Alvorada no campo [Música manuscrita]. [191-?]. Partitura ms. (1 f.) ; 21,1 x 28,8 cm.

Alvorada no campo, pf, allegretto

Partitura autógrafa(?) inacabada, ms. a lápis de carvão. Música destinada eventualmente a versos de Bulhão Pato, que aparece mencionado, e 
riscado, no canto superior direito da f. Pode ter sido pensada para integrar o ciclo Toadas da minha aldeia, composto entre 1913 e 1916.

\section{ALF M.M. 1.2 (12)}

\section{ÁRIA}

(Ver: Três peças do século XVIII)

\section{BARCAROLA}

(Ver: Composições)

\section{BERCEUSE}

(Ver: Petite suite)

\section{CANÇÃO DA NOITE}

(Ver: Composições)

\section{CANÇÃO E DANÇA PORTUGUESAS, piano}

FRAGOSO, António, (1897-1918). Canção e dança portuguezas [Música manuscrita]. [1916]. Partitura ms. ([7] p. em 3 f. dobr.) ; 29,0 x 21,0 cm.

Canção, pf, Dó $m$, devagar e expressivo

Dança, pf, Fá $\mathrm{M}$, muito alegre

Cópia a tinta preta, com assinatura indecifrável (Jorge?) no final da «Canção» (p. 3). Data da composição com base em obras de referência. Com indicação «Piano» na p. de título, riscada, e alteração da numeração original das peças, a lápis color lilás e azul. Suporte em papel «P. CAV. os», de 10 pentagramas. A escrita apresenta algumas características do manuscrito Nocturno para harpa (1918). Também disponível publicação.

\section{ALF M.M. 1.2 (13)}

\section{CANÇÃO POPULAR, piano, Fa M}

FRAGOSO, António, (1897-1918). Canção popular [Música manuscrita]. [191?]. Partitura ms. (1 f.) ; 35,0 x 27,0 cm.

Canção popular, pf, Fa M(?), allegro moderato 
Manuscrito autógrafo, a lápis. Trata-se de um exercício de composição inacabado (20 compassos), com o título emendado, anteriormente «Dansa popular». Nos primeiros pentagramas inclui um exercício de composição inutilizado pela sobreposição de dois traços cruzados; à cabeça pode ver-se o título «Canção selvagem», apagado. No verso da f., contém o início de cópia cuidada de exercício(?) para piano, com três compassos a tinta preta e a lápis.

ALF M.M. 1.2 (14)

\section{CAPRICHO, Valsas}

(Ver: Música para piano)

\section{COMPOSIÇÕES, piano}

FRAGOSO, António, (1897-1918). Composições [Música manuscrita]. [1913?].

Partitura ms. [8 p.] ; 35,0 × 26,9 cm.

Serenata, pf, Sol M, andante

Canção da noite, pf, Fá $m$

Barcarola, pf, Sol $\mathrm{m}$, andante

Berceuse, pf, Mi b M, moderato, quasi allegretto

Ingénua. Valsas, pf, Ré $M$

Cópia(?). Escrita muito cuidada, a tinta preta, seguida de rascunhos a lápis de carvão, muito rasurados e emendados a lápis e a tinta; em suporte de papel «Prosper Colas - Paris / Eduardo da Fonseca - Porto», de 10 pentagramas. Data da composição da valsa Ingénua.

Inclui: $\mathbf{I}$ - Serenata $=$ Serénade $=$ Serenade : op. 1, n० 1 (f. 1-2); II - Canção da noite $=$ Chanson de la nuit : op. 1, no 2 (f. 2-2 v.); III - Barcarola: op.1, no 3 (f. 2 v.); Rascunhos: Berceuse (sete compassos, inacabada, f. 3); Valsa [Ingénua] : Introdução (f. 3) Valsa : [Ingénua] (com pequena coda; anteriormente com o título "Recordação", riscado e substituído por "Valsa) (f. $3 \mathrm{v}-4 \mathrm{v})$. As três primeiras peças editadas por Margarida Prates (2014) p. 103-108.

\section{ALF M.M. 1.1 (f. 58-61)}




\section{CORO DOS PEREGRINOS, piano, Mi M}

FRAGOSO, António, (1897-1918). Coro dos peregrinos [Música manuscrita]. [1914]. Partitura ms. (1 f.) ; 28,8 x 21,0 cm.

Coro dos peregrinos, pf, Mi M, largo magestoso

Autógrafo, manuscrito a lápis, da transcrição para piano da partitura original para coro a 3 vozes. Datado com base em documentação disponível no Fundo. No verso da f., os 4 pentagramas iniciais estão apagados e riscados. Marcas de dobras no suporte prejudicam a leitura do $5 .^{\circ}$ pentagrama. Também disponível partitura original para coro a capella.

\section{ALF M.M. 1.2 (15)}

\section{DANÇA, piano, Fá M}

(Ver: Canção e Dança portuguesas)

\section{DANÇA, piano, Ré m}

(Ver: Petite suite)

\section{DANÇA POPULAR, piano, Do M}

FRAGOSO, António, (1897-1918). Dansa popular [Música manuscrita]. [191-]. Partitura ms. (1 f.) ; 34,8 × 27,0 cm.

Dança popular, pf, Do $\mathrm{M}$, moderato Autógrafo(?), a lápis de carvão sobre Papel «Prosper Colas - Paris / Eduardo da Fonseca - Porto», de 10 pentagramas. Pequeno exercício com 16 compassos. No verso contém um esboço de composição com 4 compassos, um dos quais rasurado.

\section{ALF M.M. 1.2 (16)}

DANÇA POPULAR, piano, Mi M

FRAGOSO, António, (1897-1918). Dansa popular [Música manuscrita]. [191-]. Partitura ms. [4 p.] ; $29,2 \times 22,0 \mathrm{~cm}$.

Dança popular, pf, Mi M, allegretto com graça

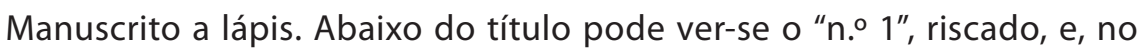
canto superior direito da f., a indicação: «lmpressa».Também disponível 
publicação, com ligeira variante na indicação do andamento: «Allegro» em vez de «Alegreto».

\section{ALF M.M. 1.2 (17)}

\section{L'EXTASE D'UNE VIÈRGE}

(Ver: Pensées extatiques)

\section{FUGA DA 1.a SONATA DE VIOLINO DE BACH, piano, Sol m}

FRAGOSO, António, (1897-1918). Fuga da 1a sonata de violino de Bach [Música manuscrita]. [entre 1917 e 1918]. Partitura ms. [4 p.] ; 30,0 x 22,7 cm.

Fuga da $1^{\text {a }}$ sonata de violino de Bach, pf, Sol $\mathrm{m}$, allegro Manuscrito inacabado, a lápis de carvão. Transcrição para piano da Fuga da

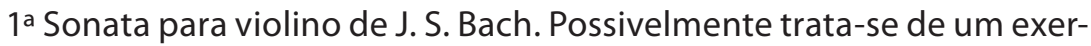
cício no âmbito da frequência do Curso Superior de Piano (Prates, 2014).

\section{ALF M.M. 1.1 (f. 246-249)}

\section{GAVOTTE}

(Ver: Três peças do século XVIII)

\section{INGÉNUA. Valsas, piano, Ré M}

FRAGOSO, António, (1897-1918). Ingenua [Música manuscrita] : valsa. [1913]. Partitura ms. (2 f.) ; 32, $3 \times 25,0 \mathrm{~cm}$.

Ingénua. Valsas, pf, Ré M

Autógrafo. Partitura incompleta, ms. a tinta preta sobre papel «L.J. \& C.ie BASSEAU», de 10 pentagramas. Data estimada com base em documentação do Fundo. Também disponível um rascunho completo, com o título «Valsa», ms. a lápis e a tinta, com variantes em alguns compassos, incluído em Composições.

\section{ALF M.M. 1.1 (f. 56-57)}

\section{INQUIETUDE}

(Ver: Música para piano) 


\section{MAZURCAS, piano}

FRAGOSO, António, (1897-1918). 3 mazurcas [Música manuscrita] : op. 2. Pocariça, 1914. Partitura ms. (10 p.) ; 29,0 x 21,0 cm.

Mazurcas. 1, pf, La m, tempo de mazurca

Mazurcas. 2, pf, Si m, com sentimento doloroso

Mazurcas. 3, pf, Fá \# m, vivo

Manuscrito assinado e datado de 7 de janeiro de 1914, na p. de título e no canto inferior direito da p. final. Com a informação: “Op. 2", a lápis, riscada (p.1). Dedicatórias: I: ao Tio Pedro de Sá Lima; II: à Sra D. Amélia Carneiro; III: a Eduardo da Fonseca Junior. Supõe-se que tenha pertencido a Maria Henriqueta, tia materna de António Fragoso, conforme indicação a lápis, muito delida, no canto superior esquerdo da p. de título. Capa ornamentada. Também disponível manuscrito a lápis das Mazurcas 1 e 2. Editada por Margarida Prates (2014) p. 109-115.

\section{ALF M.M. 1.1 (f. 62-67)}

\section{MAZURCAS, piano}

FRAGOSO, António, (1897-1918). [3] mazurcas [Música manuscrita]. [1914]. Partitura ms. [3 f.] ; 21,0 x 29,0 cm (29,0 x 21,0 cm).

Mazurcas. 1, pf, Lá m

Mazurcas. 2, pf, Si m

Rascunho a lápis de carvão das «Mazurcas» 1 e 2, das 3 Mazurkas: op. 2, Pocariça, 1914, faltando a coda na «Mazurca 1» e o compasso final na «Mazurca 2», quando comparado com a partitura a tinta; com eventuais indicações e emendas a tinta preta e vestígios de notação musical apagada. A numeração das peças está emendada: a «Mazurka 1» foi anteriormente n. 2 e a "Mazurka 2», foi n. ${ }^{\circ}$ 3. Também disponível partitura autógrafa, muito cuidada, a tinta preta,

\section{ALF M.M. $1.2(18 / 19)$}

\section{MINUETO}

(Ver: Três peças do século XVIII) 


\section{MÚSICA PARA PIANO}

FRAGOSO, António, (1897-1918). [Música para piano] [Música manuscrita].

[191-?]. Partitura ms. (8 p.) ; 28,8 x 21,2 cm.

Música para piano, pf

Inquietude, pf, La m, molto agitato

Capricho. Valsas, pf, La b M

Prelúdios românticos. 1, pf, Si b m

Rascunho a lápis de carvão, incompleto, faltando as p. iniciais. A numeração original das páginas, p. 25 a p. 32, a tinta negra, indicia que o caderno fez parte de um conjunto mais vasto. Inclui: [Música para piano] (p. 25); Inquietude: op. 3, n॰ 3 (p. 26-27); Valsa capricho (p. 28-31); Prelúdio [n. 1, dos Prelúdios românticos], incompleto, apenas 15 compassos, faltando o final (p. 32).

Também disponíveis: versão completa do «Prelúdio», em Prelúdios românticos; rascunho de uma outra «Valsa - Capricho». A peça «Inquietude» está editada por Margarida Prates (2014), p. 116.

\section{ALF M.M. 1.1 (f. 204-207)}

\section{NOCTURNE, piano, Si b m}

(Ver: Suite romantique)

\section{NOTURNOS, piano, Ré b Maior}

FRAGOSO, António, (1897-1918). Nocturno [Música manuscrita] : para piano. Lisboa, Ouct. 1917. Partitura ms. (5 p.) ; 34,7 x 27,3 cm.

\section{Noturnos, pf, Re b M}

Cópia autógrafa(?), assinada e datada; escrita muito cuidada, a tinta preta, com anots. ms. a lápis. Dedicatória: ao Mestre Snr. Luiz de Freitas Branco, à cabeça da p. de tít. Também disponíveis: rascunho a lápis, seguido de rascunho para harpa, da mesma peça, incompleto, e rascunhos de composição; cópia manuscrita, cuidada (1917), inacabada; publicação; versão orquestral, em Mi b M.

\section{ALF M.M. 1.2 (20)}




\section{NOTURNOS, piano, Ré b Maior}

FRAGOSO, António, (1897-1918). Nocturno [Música manuscrita]. 1917. Partitura ms. [2 p.] ; 30,0 $\times 22,6 \mathrm{~cm}$.

Noturnos, pf, Ré b M, lento e expressivo

Partitura assinada e datada na p. inicial, incompleta, contendo apenas 37 compassos do Noturno em Re b maior; escrita cuidada, a tinta negra. $\mathrm{O}$ mesmo caderno contém rascunho a lápis, com variantes, completo, e um rascunho para harpa, incompleto. Também disponíveis: cópia autografada; publicação; versão orquestral, em Mi b M.

\section{ALF M.M. 1.1 (f. 199-201)}

\section{NOTURNOS, piano, Ré b Maior}

FRAGOSO, António, (1897-1918). Nocturno [Música manuscrita] : em Ré b maior. 1917. Partitura ms. [4p. em 1 f. dobr.] ; 35,0 x 27,0 cm.

Noturnos, pf, Ré b M, lento e expressivo

Cópia cuidada; ms. a tinta negra, apresenta título, assinatura, data e as duas p. finais a lápis de carvão; notação e letra ligeiramente diferentes das do autor, deixando dúvidas quanto à autoria da cópia. Papel «HR» de pauta para piano, com chavetas e claves impressas. o mesmo caderno. Também disponíveis: Partitura ms. a tinta, inacabada (1917), partitura ms. a lápis, seguida de rascunho da mesma peça para harpa, incompleto; cópia autógrafa(?), muito cuidada, datada de outubro 1917; publicação; versão orquestral, em Mi b $\mathrm{M}$.

\section{ALF M.M. 1.1 (f. 202-203)}

\section{NOCTURNOS, piano, Si b m}

(Ver: Suite romantique)

\section{PAS-DE-QUATRE. Danças, pf}

FRAGOSO, António, (1897-1918). Pas-de-quatre [Música manuscrita]. [191-?]. Partitura ms. (1 f.) ; $18,7 \times 29,4 \mathrm{~cm}$. 
Pas-de-quatre. Danças, pf

Manuscrito a tinta preta. Contém, no v., 11 compassos de melodia não identificada.

ALF M.M. 1.2 (21)

\section{PENSÉES EXTATIQUES, piano}

FRAGOSO, António, (1897-1918). Pensées extatiques [Música manuscrita]. [191-?]. Partitura ms. (8 p.) ; 32,1 x 23,9 cm.

Les ruines du temple sacré, pf, Mi b m, lent (dans une grande expression) L'extase d'une vierge, pf, Ré b m, calme et doucement expressif La ville endormie, pf

Rascunho a lápis de uma obra em três partes, em que a terceira parte, «La ville endormie», está incompleta e foi rasurada (pelo autor?). Numeração original de p. a lápis, emendada, faltando as p. 9 a 12. Também disponível publicação das duas primeiras partes.

\section{ALF M.M. 1.1 (f. 190-194)}

\section{PETITE SUITE, piano}

FRAGOSO, António, (1897-1918). Petite suite [Música manuscrita] : para piano. Lisboa, jan. 1915. Partitura ms. (14 p.) ; 29,9 x 22,7 cm.

Prelúdio, pf, Si b m, andante lamentoso

Berceuse, pf, Mi b M, andantino

Dança, pf, Re m, um pouco vivo

Autógrafo assinado (p. 2); notação a tinta negra, com indicações e dedicatórias a lápis, provavelmente acrescentadas em data posterior; com a indicação "op. 5" rasurada nas p. de título e p. 2. Dedicatórias: I - Prelúdio: a Emilio Meunier; II - Berceuse: a Lourenço Cid; III - Dansa: a Fernando Leitão. Pert.: Viriato Fragoso. Também disponíveis: publicação; orquestração por Joly Braga Santos (1958), em fotocópia.

\section{ALF M.M. 1.1 (f. 81-88)}

\section{PETITE SUITE, piano}

FRAGOSO, António, (1897-1918). [Petite suite] [Música manuscrita]. [1915].

Partitura ms. [14 p.] ; 30,0 x 22,6 cm. 
Prelúdio (Ela lamenta a triste sorte), pf, Si b m, andante lamentoso

Berceuse (dos filhos que adormecem), pf, Mi b M

Dança, pf, Re m

Vindima. Canções, S pf

Rascunho a lápis, emendado e rasurado, dos três andamentos da Petite suite para piano (1915), com títulos diferentes e pequenas variantes de composição. Na «Berceuse» e na «Dança», omissão do Da capo, anotando apenas a coda. Inclui, no final: Vindima, poesia de Azul (2 p.). Também disponíveis: partitura autógrafa, datada de jan. 1915, excluindo «Vindima»; cópia autógrafa(?), ms. a tinta preta; cópia cuidada, com o pert. Viriato Fragoso; publicação; orquestração por Joly Braga Santos (1958), em fotocópia.

\section{ALF M.M. 1.2 (22/23)}

\section{PETITE SUITE, piano}

FRAGOSO, António, (1897-1918). Petite suite [Música manuscrita]. [1915]. Partitura ms. [9 p.] ; 35,0 x 26,6 cm.

Prelúdio, pf, Si b m, andante lamentoso

Berceuse, pf, Mi b M, andantino

Dança, pf, Re m

Cópia cuidada, a tinta preta, com rasuras (raspagem). Data da composição. Pert.: Viriato Fragoso, Pocariça. Também disponíveis: manuscrito autógrafo, a tinta preta; rascunho a lápis; publicação; arranjo para orquestra, por Joly Braga Santos (1958), em fotocópia.

\section{ALF M.M. 1.2 (24)}

\section{POÈME DU SOIR, piano, Mi m}

FRAGOSO, António, (1897-1918). Poème du soir [Música manuscrita]. Lisboa, jan. 1915. Partitura ms. (9 p.) ; 22,5 x 30,0 cm.

Poème du soir, pf, Mi m, lento

Autógrafo, com assinatura e data na p. de título; notação a lápis, passada a tinta negra apenas na p. inicial. Dedicatória: "Ao meu primo Carlos Fragoso", à cabeça da p. de título.

\section{ALF M.M. 1.1 (f. 75-80)}




\section{PRELÚDIO SOBRE UM TEMA DADO, piano, La $m$}

FRAGOSO, António, (1897-1918). Preludio [Música manuscrita] : sobre um thema dato. 1916. Partitura [2 p. em 1 f. dobr.] ; 34,0 x 27,2 cm.

Prelúdio sobre um tema dado, pf, La m, magestoso

Partitura autógrafa, com assinatura e data; notação a tinta preta. Com indicação do tema no canto superior direito da f. inicial e marcas de revisão, a lápis. Suporte de papel de 10 pentagramas com chavetas impressas. Parece tratar-se de um exercício de composição, possivelmente realizado no âmbito das aulas do Curso Superior de Piano.

\section{ALF M.M. 1.2 (25)}

\section{PRELÚDIOS, piano, Do M}

FRAGOSO, António, (1897-1918). Preludio [Música manuscrita]. [191-?]. Partitura (2 f.) ; 34,0 × 27,1 cm.

Prelúdios, pf, Dó M, allegretto com vivacidade

Autógrafo; escrita cuidada, a tinta preta na página inicial e a lápis de carvão nas restantes f. Suporte em papel «Beethoven-Papier No1 - H.R. Kr.» com chavetas e claves impressas. Publicação também disponível.

\section{ALF M.M. 1.1 (f. 208-209)}

\section{PRELÚDIOS, piano}

FRAGOSO, António, (1897-1918). 7 prelúdios [Música manuscrita]. 4 nov. 1915. Partitura ms. [10 p.] ; 35,1 x 26,7 cm.

Prelúdios. 1, pf, Sol m, muito vivo

Prelúdios. 2, pf, Si b M e Mi b M, muito lento

Prelúdios. 3 pf, Ré m e Fá M, allegretto com graça

Prelúdios. 4, pf, Ré $M$, allegretto molto

Prelúdios. 5, pf, Ré b M, calmo

Prelúdios. 6, pf, Sol \# m

Prelúdios. 7, pf, Sol M, vivo

Autógrafo assinado e datado, ms. a lápis, No título, o número foi acrescentado posteriormente. Numeração original das peças riscada e emendada; a última f., inumerada, em papel de outra proveniência, «Beethoven- 
-Papier No1, H.R.Kr.», foi provavelmente acrescentada em data posterior. Também disponível publicação.

\section{ALF M.M. 1.1 (f. 136-140)}

\section{PRELÚDIOS, piano, Si b M}

(Ver: Petite suite)

\section{PRELÚDIOS ROMÂNTICOS, piano}

FRAGOSO, António, (1897-1918). Preludios românticos [Música manuscrita]. [1914?]. Partitura ms. (13 p.) ; $300 \times 227$ mm.

Prelúdios românticos. 1, pf, Si b m, lento ; com profunda tristeza

Prelúdios românticos. 2, pf, Fá m, andante expressivo

Prelúdios românticos. 3, pf, Ré b $\mathrm{M}$

Prelúdios românticos. 4, pf, Mi m, vivo

Autógrafo; notação muito cuidada, a tinta negra, com emendas evidenciando revisão, provavelmente em época posterior. Data com base em documentação disponível no Fundo ALF/Ms. Com a indicação «Op. 3» (p. 1) e um compasso no final, riscados. Inclui indicações metronómicas. Também disponíveis rascunhos do $10^{\circ}$ (muito incompleto) e do $4 .^{\circ}$ andamentos.

\section{ALF M.M. 1.1 (f. 68-74)}

\section{PRELÚDIOS ROMÂNTICOS, piano. 1, Si b m}

(Ver: Música para piano)

\section{PRELÚDIOS ROMÂNTICOS, piano. 4, Mi m}

FRAGOSO, António, (1897-1918). Preludio 4 [Música manuscrita]. [1914?]. Partitura ms. (1 f.) ; 29,5 × 21,6 cm

Prelúdios românticos, pf. 4, Mi m, vivo

Rascunho a lápis de carvão. Trata-se da quarta peça dos Prelúdios românticos. Inclui indicação metronómica. Também disponíveis: cópia cuidada da obra completa; rascunho muito incompleto do $1^{\circ}$ andamento.

\section{ALF M.M. 1.2 (26)}




\section{RAPSÓDIAS, piano}

FRAGOSO, António, (1897-1918). Rapsodia no 1 [Música manuscrita]. [191-?].

Partitura ms. [2 p.] ; $34,9 \times 26,8 \mathrm{~cm}$.

Rapsódia, pf, Molto alegro

Autógrafo, ms. a lápis, emendado, incompleto. Contém indicações metronómicas.

ALF M.M. 1.2 (27)

\section{LES RUINES DU TEMPLE SACRÉ}

(Ver: Pénsées extatiques)

\section{SERENATA}

(Ver: Composições)

\section{SONATAS, piano, Mi m}

FRAGOSO, António ((1897-1918)). Sonata [Música manuscrita] : para piano. Lisboa, 1915. Partitura ms. (26 p.) ; 34,0 × 26,5 cm.

Sonatas, pf, Mi m, I: Muito agitado, e impetuoso; II: Calmo e cantado com doçura; Final, III: Magestoso

Manuscrito autógrafo(?); notação muito cuidada a tinta negra, com rasuras, emendas e indicações a lápis. Papel «B. C. / No 1», de 10 pentagramas. Dedicatória ao Mestre Marcos Garin, à cabeça da p. de título. Também disponíveis: cópia por J. H. Negrão, 1936; publicação, com revisão de Florinda Santos (1971).

\section{ALF M.M. 1.1 (f. 89-102)}

\section{SONATAS, piano, Mi m}

FRAGOSO, António, (1897-1918). Sonata [Música manuscrita] : para piano (Lisboa, 1915). Cantanhede, jun. 1936. Cópia, por J. H. Negrão. Partitura ms. $(20$ p.) ; $35,7 \times 26,4 \mathrm{~cm}$.

Sonatas, pf, Mi m; l: Muito agitado e impetuoso; um pouco menos marcado o canto e com muita expressão; Il: Calmo e cantado (anteriormente: 
cantando) com doçura; Final: III: maestoso; allegro ma non tropo; mais lento e alargando sempre; muito lento

Cópia de composição de António Fragoso, Lisboa, 1915, com dedicatória ao Mestre Marcos Garin. Escrita muito cuidada, a tinta azul de diferentes tons, com correções e anots. a lápis de carvão e revisão(?) a lápis color vermelho. Tem à cabeça da p. de título a anot. ms. a lápis: "2. ' caderno". Numeração de f. original a tinta, riscada, substituída por paginação, a lápis. Pert.: Viriato Fragoso, Pocariça. Também disponíveis: partitura autógrafa(?); publicação com revisão de Florinda Santos.

ALF M.M. 1.2 (28)

\section{SUITE ROMANTIQUE, piano. 4, Si b m}

FRAGOSO, António, (1897-1918). Nocturno [Música manuscrita] : da suite para violino e piano. Transcripto pelo auctor. 1916. Partitura ms. (5 p.) ; $34,9 \times 27,2 \mathrm{~cm}$.

Noturne, pf, Si b m, calmo e numa atmosfera de mistério

Cópia muito cuidada do quarto andamento da Suite [romantique], para violino e piano em suporte de papel «Prosper Colas - Paris», de 12 pentagramas. Também disponíveis: outra transcrição, sem data; parte de violino da Suite [romantique]; versão para piano, com o título Nocturno em Sib menor; publicação da partitura completa; versão(?) para orquestra de cordas por Vasco Mendonça, 2012, em fotocópias.

\section{ALF M.M. 1.1 (f. 185-187)}

\section{SUITE ROMANTIQUE, piano. 4, Si b m}

FRAGOSO, António, (1897-1918). Nocturno [Música manuscrita] : da suite para violino e piano. 1916. Transcripto pelo auctor. Partitura ms. (5 p.) ; $34,9 \times 27,2 \mathrm{~cm}$.

Nocturne, pf, Si b m, calmo e numa atmosfera de mistério

Cópia autógrafa(?), ms. a tinta negra, do quarto andamento da Suite [romantique], para violino e piano. Suporte de papel «Prosper Colas - Paris», de 12 pentagramas. Também disponíveis: outra cópia autógrafa(?), datada; parte de violino da Suite [romantique], para violino e piano; versão para 
piano, com o título Nocturno em Sib menor; publicação da partitura completa; versão (?) para orquestra de cordas por Vasco Mendonça, 2012.

\section{ALF M.M. 1.2 (29)}

\section{TRÊS PEÇAS DO SÉCULO XVIII, piano}

FRAGOSO, António, (1897-1918). [Três peças do século XVIII] [Música manuscrita]. [1917]. Partitura ms. [2 f.] ; 29,4 × 22,4 cm (21,9 x 30,0 cm).

Minueto, pf, Dó M, moderato

Ária, pf, Sol $\mathrm{m}$, lento

Gavotte, pf, Sol M

Título da publicação. Datação com base em documentação disponível no Fundo. Rascunhos a lápis de carvão em suporte de papel de proveniências diversas. Também disponível partitura com a melodia da «Ária» na clave de Fá, possivelmente uma transcrição para violoncelo (Prates, 2014).

\section{ALF M.M. 1.1 (f. 220-221)}

\section{VALSAS. Capricho, piano, Mi m}

FRAGOSO, António, (1897-1918). Valsa capricho [Música manuscrita]. [191-?]. Partitura ms. (1 f.) ; 28,8 x 20,8 mm.

Valsa capricho, pf, Mi m(?), vivo e com graça

Partitura autógrafa(?), ms. a lápis, inacabada. Também disponível um rascunho de outra peça com o mesmo título.

\section{ALF M.M. 1.2 (30)}

\section{VALSAS. Capricho, piano, La b $\mathbf{m}$}

(Ver: Música para piano)

\section{LA VILLE ENDORMIE}

(Ver: Pensées extatiques)

\section{VOLKSWEISE}

FRAGOSO, António, (1897-1918). Volksweise [Música manuscrita] : canto popular. [191-?]. Partitura ms. ([1] p. em 1 f. dobr.) ; $27,0 \times 30,0 \mathrm{~cm}$. 
Volksweise, pf, Sol m, l: allegretto gracioso; Il: quasi andante; Ill: allegretto; IV: quasi adagio

Autógrafo(?), ms. a lápis. Pode tratar-se de um dos primeiros exercícios de composição de António Fragoso (Prates, 2014). Na p. final, encontra-se um apontamento musical (8 compassos) inacabado, não identificado. Também disponível cópia de outra mão, a tinta azul.

\section{ALF M.M. 1.1 (f. 250-251)}

\section{VOLKSWEISE}

FRAGOSO, António, (1897-1918). Volksïveise [sic] [Música manuscrita] : canto popular. [191-?]. Partitura ms. (1 f.) ; $23,3 \times 26,0 \mathrm{~cm}$.

Volksweise, pf, Sol m. I: Allegretto gracioso; Il: quasi andante; Ill: allegretto; IV: quasi adagio.

Cópia, ms. a tinta azul. Também disponível autógrafo.

\section{ALF M.M. 1.2 (31)}

\subsubsection{Violino}

\section{TOADAS DA MINHA ALDEIA, violino}

FRAGOSO, António, (1897-1918). [Toadas da minha aldeia] [Música manuscrita]. [191-]. 1 pc : vl ; 21,8 $29,2 \mathrm{~cm}$.

Cantares. Canções, vl, Re m, andante

Canção perdida. Canções, vl, Re m, andante doloroso

Cantiga do campo. Canções, vl, La m, moderato

Parte de violino de três das cinco peças da obra impressa; tendencialmente duplica a voz mais aguda da versão publicada. Manuscrito a tinta preta, assinado; em suporte de papel «THOMAR», de 10 pentagramas. Publicação também disponível.

\section{ALF M.M. 1.2 (32)}




\subsubsection{Violoncelo}

\section{TRÊS PEÇAS DO SÉCULO XVIII, piano. Ária, violoncelo, fá}

FRAGOSO, António, (1897-1918). Aria [Música manuscrita]. [1917?]. Partitura ms. (1 f.) ; $29,9 \times 22,8 \mathrm{~cm}$.

Ária, vcl, Fa, lento

Manuscrito a tinta negra, sem assinatura. Parece tratar-se de um exercício de transposição para violoncelo da segunda peça do ciclo para piano Três peças do século XVIII (Prates, 2014). Também disponíveis: partitura manuscrita; publicação do ciclo completo.

ALF M.M. 1.2 (33)

\subsection{Música Religiosa}

\section{CÂNTICO PARA DEPOIS DA CATEQUESE}

FRAGOSO, António, (1897-1918). Cantico para depois da catequese [Música manuscrita]. 1918. Partitura ms. ([3] p. em 1 f. dobr.) ; 30,0 x 22,7 cm.

Cântico para depois da catequese, Ssolo Coro(S) e harmónio, Do M, lento expressivo

Música para versos do Padre Silva Gonçalves. Partitura autógrafa(?) a tinta preta, assinada e datada. Tem junto manuscrito da letra, numerado à cabeça da p. de título: «2».Também disponível rascunho a lápis, com menos dois compassos no final.

\section{ALF M.M. 1.1 (f. 254-255)}

\section{CÂNTICO PARA DEPOIS DA CATEQUESE}

FRAGOSO, António, (1897-1918). Cantico para depois da catequese [Música manuscrita]. [1918]. Partitura ms. [2 p.] ; 30,0 x 22,7 cm.

Cântico para depois da catequese, Ssolo Coro(S) e harmónio, Do M Rascunho a lápis de carvão. Também disponível partitura manuscrito a tinta, com dois compassos mais no final.

\section{ALF M.M. 1.1 (f. 257)}




\section{HINO DA CATEQUESE}

FRAGOSO, António, (1897-1918). Hino da catequese [Música manuscrita] : para a diocese do Porto. 1918. Partitura ms. ([3] p. em 1 f. dobr.) ; 30,0 × 22,7 cm.

Hino da catequese, Ssolo Coro(S) e harmónio, Mi b M, lento, mas não muito Partitura autógrafa(?), assinada e datada na p. de título, com notação e letra a tinta preta. Também disponível rascunho a lápis com ligeiras diferenças na indicação de andamento e no final (falta a coda).

\section{ALF M.M. 1.1 (f. 252-253)}

\section{HINO DA CATEQUESE}

FRAGOSO, António, (1897-1918). Hino da catequese [Música manuscrita]. [1918]. Partitura ms. [2 p.] ; 30,0 x 22,7 cm.

Hino da catequese, Ssolo Coro(S) e harmónio, Mi b M, lento religioso Rascunho a lápis. Também disponível cópia autógrafa(?) da qual difere pela indicação do andamento «Lento mas não muito» e pelo final, onde acresce uma pequena coda.

\section{ALF M.M. 1.1 (f. 256)}

\subsection{Exercícios de Composição}

\section{EXERCÍCIOS DE COMPOSIÇÃO}

FRAGOSO, António, (1897-1918). Exercício no 1 ; n² 2 [Música manuscrita]. [191-?]. Partitura ms. [2 f.] ; 32,2 $\times 24,0 \mathrm{~cm}(29,3 \times 22,5 \mathrm{~cm})$.

Manuscritos sem assinatura e sem data. Notação a tinta azul com emendas e anots. a lápis e a tinta. São dois exercícios de música de câmara(?), de 13 e de 32 compassos respetivamente, incluindo ambos, no final, um apontamento musical.

\section{ALF M.M. 1.2 (34)}

\section{EXERCÍCIOS DE COMPOSIÇÃO}

FRAGOSO, António, (1897-1918). [Exercícios de composição] [Música manuscrita]. Maio 1917. Partitura ms. (1 f.) ; 21,8 x 30,0 cm. 
Autógrafo. Exercício de música de câmara(?), 20 compassos, a tinta azul, seguido de composição para piano (18 compassos), a lápis de carvão. No final podem ver-se cinco exercícios de assinatura do nome António, a lápis.

\section{ALF M.M. 1.2 (35)}

\section{EXERCÍCIOS DE COMPOSIÇÃO}

FRAGOSO, António, (1897-1918). [Exercício de composição?] [Música manuscrita]. [1917]. Partitura ms. (1 f.) ; 22,2 x 30,3 cm.

Música para piano. Autógrafo(?), ms. a tinta preta, incompleto, apresentando apenas 15 compassos finais.

\section{ALF M.M. 1.2 (36)}

\subsection{Manuscritos de Autoria Indeterminada}

\section{AVÉ MARIA. Hinos}

Ave Maria no 3 ; Ladainha no 4 (modificada) [Música manuscrita]. [S.d.]. Partitura ms. (1 f.) ; 29,6 x 21,4 cm.

Avé Maria, V

Ladainha de Nossa Senhora, V

Notação e letra a tinta azul. Não parece escrita de António Fragoso. O final da ladainha (2 pentagramas) encontra-se a seguir à Avé Maria.

\section{ALF M.M. 1.2 (37)}

\section{DANÇAS, flauta}

Contradanças [Música manuscrita]. [s.d.]. Partitura ms. (1 f.) ; 21,3 x 29,5 cm.

Manuscrito a tinta preta. No canto superior direito da frente lê-se: «V.S.Fragoso» (Viriato de Sá Fragoso). No verso, uma segunda «Contradança» (apenas o início) foi riscada. Inclui: Contradanças: 1a a $5^{a}$ (frente); Contradanças: 1a; Visão (valsa) (verso).

\section{ALF M.M. 1.2 (38)}




\section{DANÇAS, flauta}

Sac au dos! ; He son[?] [Música manuscrita]. [s.d.]. Partitura ms. [2 p.] ; 21,7 $x 29,5 \mathrm{~cm}$.

Manuscrito a tinta preta, sem assinatura e sem data. Não parece escrita de António Fragoso.

\section{ALF M.M. 1.2 (39)}

\section{DANÇAS, flauta}

Tango ; Contradança ; My Enreen[?] ; Polka, Rec. de Amizade [Música manuscrita]. [S.d.]. Partitura ms. [1 f.] ; 21,5 x 29,4 cm.

Manuscrito a tinta preta com múltiplas assinaturas de V.S. Fragoso (Viriato de Sá Fragoso) no canto superior e na margem esquerdos da frente e no canto superior direito do verso (V.S.F.); no canto superior direito da f. contem a indicação «Flauta»; na margem inferior tem: J. G. Gonçalves(?).

\section{ALF M.M. 1.2 (40)}

\section{Música Impressa}

\subsection{Música Vocal}

\subsubsection{Música para Canto e Piano}

\section{CANÇÃO PERDIDA. Canções, Si m}

(Ver: Toadas da minha aldeia)

\section{CANÇÕES DO SOL POENTE}

FRAGOSO, António, (1897-1918). Canções do sol poente [Música impressa]. Revisão de Fernando Lopes-Graça. In António Fragoso: obras póstumas. II. Lisboa : [Valentim de Carvalho], 1971. Partitura (p. 4-23) ; 33 cm.

Música para versos de António Correia de Oliveira: I - Canção da fiandeira (tom original: Fá sust. maior), allegreto (p. 4-5); II - Embalando o menino (tom original) Ré b M, tempo de berceuse (p. 6-7); III - Modas da serra (tom original) Fá sust. menor) tristemente (p. 8); IV - A primeira romaria 
(tom original: Lá maior) (p. 9-10); V - A manhã de Serração (tom original: Dó maior) (p. 11-13); VI - O Natal do céu (tom original: Lá menor) (p. 14-17); VII - A Senhora dos Remédios (p. 18-20), Ré menor; Cantigas do lenço (tom original), Si m, com melancolia (p. 21-23).

\section{ALF M.M. 1.3 (8)}

\section{CANTARES. Canções, Ré $m$}

(Ver: Toadas da minha aldeia)

\section{CANTIGA DO CAMPO. Canções, Lá m}

(Ver: Toadas da minha aldeia)

\section{CANTIGAS DA NOSSA TERRA}

(Ver: Toadas da minha aldeia)

\section{CHANSON D'AUTOMNE}

(Ver: Poémes saturniens)

\section{CONSOLATION. Canções}

FRAGOSO, António, (1897-1918). Consolation [Música impressa].: para piano e canto. Versos de Fernand Grech. A semana musical, Ano I, no 16 (26 abr. 1923), 2-3.

Consolation. Canções, S pf, Sol M, andantino

Publicado com artigo de Oliva Guerra sobre António de Lima Fragoso ( $p$. 8). Data da composição: dez. 1915. A revista inclui: "Elegia, op. 38, no 6: allegreto semplice", de E. Grieg (p. 4); "Prelúdio, op. 28, n 18", de Chopin (p. 5); e "Mignon: fox-trot: moderato", de Harold de Bozi (p. 6-7), inutilizadas.

\section{ALF M.M. 1.1 (f. 52-55)}

\section{LES COQUILLAGES. Canções, piano, La m}

FRAGOSO, António, (1897-1918). Les coquillages [Música impressa]. Revisão de Fernando Lopes-Graça. In António Fragoso : obras póstumas. II. Lisboa : [Valentim de Carvalho], 1971. Partitura (p. $36-38) ; 33 \mathrm{~cm}$. 
Les coquillages, S pf, La m

Música para canto e piano sobre versos de Paul Verlaine.

ALF M.M. 1.3 (8)

\section{MORENA. CANÇÕES, Mi m}

(Ver: Toadas da minha aldeia)

\section{POÈMES SATURNIENS. Canções}

FRAGOSO, António, (1897-1918). Poèmes saturniens» [Música impressa]. Revisão de Fernando Lopes-Graça. In António Fragoso: obras póstumas. II. Lisboa : [Valentim de Carvalho], 1971. Partitura (p. 24-32) ; 33 cm.

Música para voz (S) e piano sobre versos de Paul Verlaine. Inclui: I - Soleils couchants, Mi b m, lent, dans une atmophère de mystère (p. 24-27); II

- Sérénade (tom original: Fá menor), modérément animé (p. 28-32); III - Chanson d'Automne (tom original: Fá sust. menor) modéré (p. 33-35).

ALF M.M. 1.3 (8)

\section{TOADAS DA MINHA ALDEIA. Canções}

FRAGOSO, António, (1897-1918). Toadas da minha aldeia [Música impressa] : canções a uma e duas vozes : cinco canções portuguezas sobre versos dos nossos poetas. Lisboa : Valentim de Carvalho, [1916]. Partitura (15 p.) ; $24 \mathrm{~cm}$.

Cantigas da nossa terra, SS pf, Sol M, devagar e indolente Cantares, S pf, Ré m, lento

Canção perdida, SS pf, Si m, andante

Cantiga do campo, S pf, Lá m, moderato

Conteúdo: I - Cantigas da nossa terra, a duas vozes. Versos de Vicente Arnoso. Dedicatória: "Às senhoras que primeiro a cantaram em 1 de Janeiro de 1913"; II - Morena, a duas vozes. Versos de Julio Diniz. Dedicada: "À memória de Julio Diniz"; III - Cantares, a uma voz. Versos de Marcelino Mesquita. Dedicada: "A minhas irmãs"; IV - Canção perdida, a uma e duas vozes. Versos de Guerra Junqueiro. Dedicada: "A meu tio Dr. António dos Santos Tovim"; V - Cantiga do campo, a uma voz. Versos de Gomes Leal. Dedicada: "Ao Jorge da Cruz Jorge". 
ALF M.M. 1.1 (f. 31-41). Com dedicatória autógrafa de António Fragoso aos pais e aos irmãos, datada de 16 maio 1916.

\section{TRISTE ÉTAIT MON ÂME. Canções, Mi m}

FRAGOSO, António, (1897-1918). Triste était mon Âme [Música impressa].

Revisão de Fernando Lopes-Graça. In António Fragoso : obras póstumas.

II. Lisboa : [Valentim de Carvalho], 1971. Partitura (p. 39-40) ; 33 cm.

Música para canto e piano sobre versos de Paul Verlaine.

ALF M.M. 1.3 (8)

\subsection{Música Instrumental}

\subsubsection{Música para Orquestra}

\section{NOTURNOS, Mi b}

FRAGOSO, António, (1897-1918). Nocturno [Música impressa]. Revisão e estudo [de] Jorge Croner de Vasconcellos. Lisboa : Fundação Calouste Gulbenkian, 1968. Partitura (30 p.) e pc ; 31 cm. (Portugaliae musica. Série $C$; 18).

Noturnos, orch (2fl 2ob corn ing 2cl 2fag 4corn 2vl vla vlc cb harp), Mi b Chapa n Pm 1018. Dedicatória: «Ao meu mestre Sr. Luiz de Freitas Branco». Edição bilingue em português e francês. Disponível em Manuscritos.

\section{ALF M.M. 1.3 (5/6)}

\subsubsection{Música de Câmara}

\section{SONATAS. Allegro, violino e piano, Re M}

FRAGOSO, António, (1897-1918). Allegro da sonata (inacabada) em ré maior para violino e piano [Música impressa] : «opus 3». Revisão de Artur Santos e Lídia de Carvalho (colab). In António Fragoso: obras póstumas. III. Lisboa : [Valentim de Carvalho], 1971. Partitura (p. 83-100); 33 cm.

Sonatas. Allegro, vl pf, Ré M, magestoso / allegro moderato Também disponíveis manuscritos. 


\section{SUITE ROMANTIQUE, violino e piano}

FRAGOSO, António, (1897-1918). Suite romantique [Música impressa]. Revisão de Álvaro Cassuto. In António Fragoso : obras póstumas. III. Lisboa : [Valentim de Carvalho], 1971. Partitura (p. 3-25) ; $33 \mathrm{~cm}$.

Prélude, vl pf, Dó $M$, modéré

Intermezzo, vl pf, Sol $\mathrm{m}$, trés passioné

Berceuse, vl pf, Fá $M$, très moderé

Nocturne, vl pf, Si b m, calme et doucement

ALF M.M. 1.3 (9)

\section{TRIO, violino, violoncelo e piano, Dó \# m}

FRAGOSO, António, (1897-1918). Trio em Dó sustenido menor para piano, violino e violoncelo [Música impressa] : «opus 2». Revisão de Filipe Pires. In António Fragoso : obras póstumas. III. Lisboa : [Valentim de Carvalho], 1971. Partitura (p. 30-82) ; $33 \mathrm{~cm}$.

Trio, vl vlc pf, Dó \# m, I - Allegro moderato; Il - Muito lento; III - Scherzo: muito vivo; IV - Final: allegro vivo.

\section{ALF M.M. 1.3 (9)}

\subsubsection{Música para Piano}

\section{CANÇÃO E DANÇA PORTUGUESAS, piano}

FRAGOSO, António, (1897-1918). Canção e dança portuguezas [Música impressa] : para piano. Lisboa : Valentim de Carvalho, [193-?]. Partitura (5 p.) $; 34 \mathrm{~cm}$.

Canção, pf, Dó m, devagar e expressivo

Dança, pf, Fá M, muito alegre

Dedicatória à cabeça da p. inicial: "Para as creanças que tocam piano na minha aldeia".

\section{ALF M.M. 1.1 (f.49-51)}


ALF M.M. 1.3 (1) Exemplar em mau estado de conservação.

\section{DANÇA POPULAR, piano}

FRAGOSO, António, (1897-1918). Dança popular [Música impressa] : para piano. Lisboa : Valentim de Carvalho, [193-?]. Partitura (3 p.) ; 34 cm.

Dança popular, pf, Mi M, allegro com graça

ALF M.M. 1.1 (f.47-48)

ALF M.M. 1.3 (10)

ALF M.M. 1.2 (32). Exemplar muito marcado pelo uso, com anotações ms. na capa

\section{NOTURNOS, piano, Si b m}

FRAGOSO, António, (1897-1918). Nocturno em Sib menor [Música impressa] :

Da suite para violino e piano. In Composições para piano. $2 .^{\circ}$ cad. ${ }^{\circ}$. Lisboa : Valentim de Carvalho, [1923]. Partitura (p. 2-6) ; $30 \mathrm{~cm}$.

Noturnos, pf, Si b m, calmo e numa atmosfera de mistério

Transposição para piano de um andamento da «Suite para violino e piano» ou Suite romantique.

ALF M.M. 1.1. (f. 17-29)

\section{NOTURNOS, piano, Re b m}

FRAGOSO, António, (1897-1918). Nocturno em Reb maior [Música impressa]. In Composições para piano. 2. ${ }^{\circ}$ cad. ${ }^{\circ}$. Lisboa : Valentim de Carvalho, [1923]. Partitura (p. 7-15) ; $30 \mathrm{~cm}$.

Noturnos, pf, Re b M, lento e expressivo Dedicatória a Luís de Freitas Branco. Disponível em Manuscritos.

ALF M.M. 1.1. (f. 17-29)

\section{PENSÉES EXTATIQUES, piano}

FRAGOSO, António, (1897-1918). Pensées extatiques [Música impressa]. In Composições para piano. $2 .^{\circ}$ cad. ${ }^{\circ}$. Lisboa : Valentim de Carvalho, [1923]. Partitura (p. 16-21) ; $30 \mathrm{~cm}$. 
Les ruines du temple sacré, pf, com muita expressão

L'extase d'une vierge, pf, calmo e docemente expressivo

\section{ALF M.M. 1.1. (f. 17-29)}

PETITE SUITE, piano

FRAGOSO, António, (1897-1918). Petite suite [Música impressa]. In Composições para piano. 1. ${ }^{\circ} \mathrm{cad}$. . Lisboa : Valentim de Carvalho, [1923]. Partitura (p. 5$) ; 30 \mathrm{~cm}$.

Prélude, pf, Si b m, andante lamentoso com muita expressão

Berceuse, pf, Mi b M, andantino

Dança, pf, Re $m$, um pouco vivo

Dedicatórias a: Emílio Dória Meunier; Lourenço Varela Cid Júnior; Fernando Botelho Leitão.

\section{ALF M.M. 1.1 (f. 1-16)}

\section{PRELÚDIOS, piano, Do M}

FRAGOSO, António, (1897-1918). Prelúdio [Música impressa]. In Composições para piano. $2 .^{\circ} \mathrm{cad} .{ }^{\circ}$. Lisboa : Valentim de Carvalho, [1923]. Partitura (p. $12-15) ; 30 \mathrm{~cm}$.

Prelúdios, pf, Dó M, alegreto com vivacidade Dedicatória a Maria Luísa Garin.

\section{ALF M.M. 1.1. (f. 17-29)}

\section{PRELÚDIOS, piano}

FRAGOSO, António, (1897-1918). 7 Prelúdios [Música impressa]. In Composições para piano. $1 .^{\circ} \mathrm{cad}$. . Lisboa : Valentim de Carvalho, [1923]. Partitura (p. 18-27) ; $30 \mathrm{~cm}$.

Prelúdios. 1, pf, Sol m, muito vivo

Prelúdios. 2, pf, Si b M e Mi b M, muito lento

Prelúdios. 3 pf, Ré m e Fá $M$, allegretto com graça

Prelúdios. 4, pf, Ré $\mathrm{M}$, allegretto molto

Prelúdios. 5, pf, Ré b $\mathrm{M}$, calmo

Prelúdios. 6, pf, Sol \# m, andantino 
Prelúdios. 7, pf, Sol M, vivo

\section{ALF M.M. 1.1 (f. 1-16)}

\section{SONATAS, piano, Mi menor}

FRAGOSO, António, (1897-1918)

Sonata em Mi menor para piano [Música impressa]. Revisão de Florinda Santos. In: António Fragoso : obras póstumas.1. Lisboa : Valentim de Carvalho, 1971. Partitura (28 p.) ; $33 \mathrm{~cm}$.

Sonatas, pf, Mi m

\section{ALF M.M. 1.3 (7)}

\section{SUITE ROMANTIQUE, piano. Nocturne}

(Ver: Noturnos, piano, Si b m)

\section{TRÊS PEÇAS DO SÉCULO XVIII, piano}

FRAGOSO, António, (1897-1918). Três peças do século XVIII [Música impressa] : para piano. Lisboa : Valentim de Carvalho, [1917]. Partitura (3 p.) ; 34 cm.

Minueto, pf, Dó $\mathrm{M}$, moderato

Ária, pf, Sol m, lento

Gavotte, pf, Sol M, tempo de gavotte

Dedicatória: a Vasco Garin.

ALF M.M. 1.1 (f. 42-46). Com dedicatória autógrafa de António Fragoso aos pais, datada de abril de 1917; com rasuras e anotações ms. a lápis de carvão

ALF M.M. 1.3 (2). Com dedicatória autógrafa de António Fragoso ao irmão Carlos, datada de abril de 1917

\section{ALF M.M. 1.3 (3)}

ALF M.M. 1.3 (4). Possivelmente impressão mais recente (1960?). Com dedicatória autógrafa de Maria Fernanda (Fragoso Martins Soares) a um neto e anotações ms. a lápis e a tinta; muito manchado pelo manuseamento; com marcas de restauro 


\section{Impressões e Fotocópias: Arranjos e Orquestrações}

\section{NOTURNOS, piano, Si b menor. Arranjo}

FRAGOSO, António, (1897-1918). Nocturno em sib menor [Música impressa]

: versão para orquestra de cordas. Orquestação de Vasco Mendonça. [S. I.] : [s. n.], 2012. Partitura (17 f.) ; 29,7 x 21,0 cm.

Noturnos, pf, Si b m; arr (vl1 vl2 vlc cb)

Cópia da partitura geral da versão orquestral do Noturno em Sib menor, para piano. A impressão original ostenta dedicatória autógrafa de Vasco Mendonça a Eduardo Fragoso, na p. de rosto.

\section{ALF M.M. 1.4 (1)}

\section{PETITE SUITE, piano, arranjo}

FRAGOSO, António, (1897-1918). Pequena suite [Música manuscrita]. Versão orquestral de Joly Braga Santos. [S. I.] : [s.n.], [1958]. 36 pc ms. ; 36,0 x $27,3 \mathrm{~cm}$.

Petite suite, pf; arr. Pc: 2 vl vla vlc cb 1fl 2fl 3 fl pic 1ob 2ob cor ing 1cl sib 2cl sib cl baixo sib 1 fag 2 fag contra-fag 1cor fá 2cor fá 3cor fá 4cor fá 1tr dó 2 tr dó 3 tr dó 1 trb 2 trb 3 trb tuba bombo pratos caixa triângulo tan-tan timbales 1harp 2harp celesta

Fotocópia (p\&b) das partes cavas da versão orquestral, por Joly Braga Santos, da obra de António Fragoso Petite suite, para piano, de 1915. Datação do arranjo com base em obras de referência. Os originais ostentam carimbo do timbre: «Emissora Nacional - Arquivo Musical» e «N de registo 10852».

Algumas partes apresentam assinaturas autógrafas, locais e datas (14-81980) (25-9-82) (8-6-87) (23-6-88?), muito provavelmente respeitantes a interpretações: Romero Pai (1a flauta); António Serafim (Maestro Silva Pereira) ( $2^{\circ}$ oboé); A.Romero ( $1^{\circ}$ clarinete); Álvaro Cunha ( $1^{\circ}$ fagote); Alan Cuil, Jaime Guerreiro, António Costa, Vitorino Marquez (1a trompa); Madureira ( $3^{\circ}$ trompa); H. Campos, Maestro Silva Pereira ( $1 \circ$ trombone); A. Jubilot ( $2^{\circ}$ trombone).

ALF M.M. 1.4 (2) 


\section{PRELÚDIOS, piano, arranjo}

FRAGOSO, António, (1897-1918). Três prelúdios [Música manuscrita]. Versão orquestral de Joly Braga Santos. Porto, 1958. Partitura ms. [8 p.] ; 50,0 $x 27,0 \mathrm{~cm}$

Prelúdios, pf; arr (2fl 2cl vl1 vl2 vla vlc cb harp), l: Allegretto molto; Il: Calmo; III: Allegretto

Fotocópia. Data do original. O original ostenta carimbos do timbre «Emissora Nacional - Arquivo Musical» e o «Nº de registo: 10851».

\section{ALF M.M. 1.4 (3)}

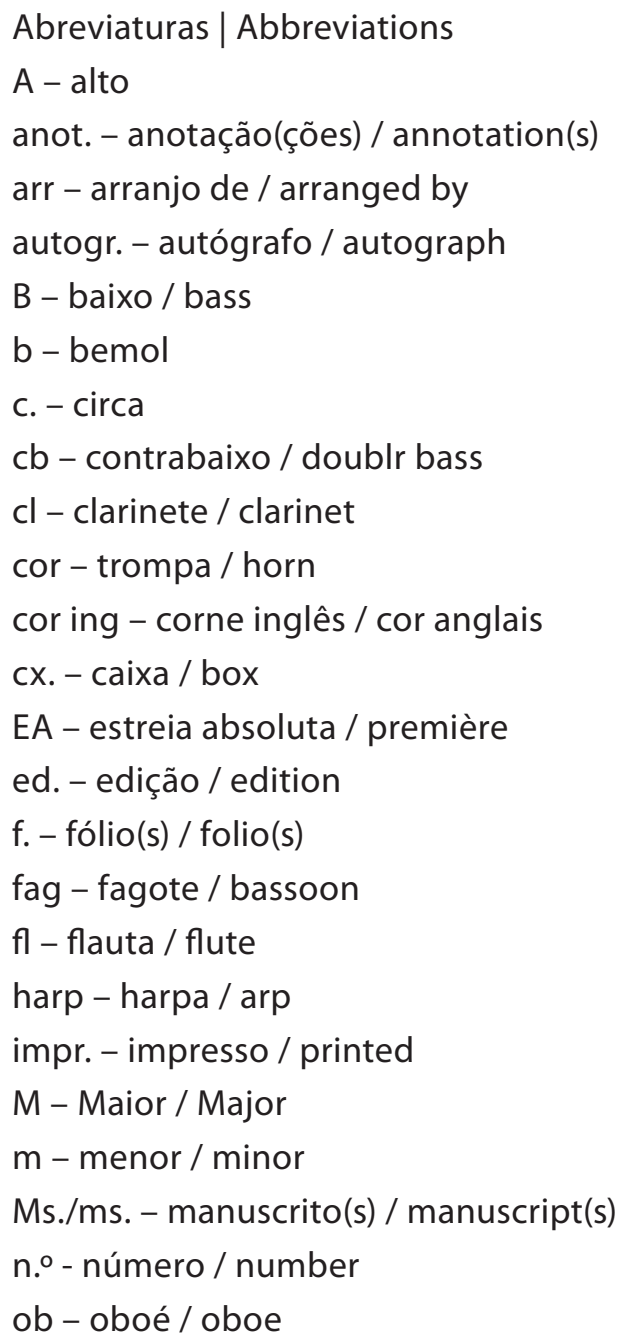


p. - página(s) / page(s)

pc - parte(s) cava(s) / part(s)

pert. - pertences / indications of ownership

pf - piano / piano

pic - flautim / piccolo

$r$ - frente da folha / front

S - soprano

sax - saxofone / saxofone

s. d. - sem data / no date

s. I. - sine loco / sem lugar / no place

$\mathrm{T}$ - tenor

tit. - título/ title

tr - trompete / trumpet

trad. - tradução / translation

trb - trombone

$v$ - verso / back

$\mathrm{vl}$ - violino / violin

vla - viola de arco / viola

vlc - violoncelo / cello

vol. - volume 